\title{
Breastfeeding intentions, patterns, and determinants in infants visiting hospitals in La Paz, Bolivia Jonas F Ludvigsson*
}

\author{
Address: Paediatric Department, Örebro University Hospital, 70185 Örebro, Sweden \\ Email: Jonas F Ludvigsson* - jonasludvigsson@yahoo.com \\ * Corresponding author
}

This article is available from: http://www.biomedcentral.com/|47|-243I/3/5

(C) 2003 Ludvigsson; licensee BioMed Central Ltd. This is an Open Access article: verbatim copying and redistribution of this article are permitted in all media for any purpose, provided this notice is preserved along with the article's original URL.

\begin{abstract}
Background: Recent ecological research from Latin America has shown that infant health could be promoted through exclusive breastfeeding in infants aged $0-3$ months and partial breastfeeding throughout the remainder of infancy.

Methods: In a cross-sectional study in 1995, the author interviewed 518 mothers with infants $\leq$ I year in La Paz, Bolivia, to describe the breastfeeding pattern and its determinants including socioeconomic, religious and ethnic background.

Results: The rate of any breastfeeding remained above $85 \%$ during the first year. Exclusive breastfeeding rates fell from $89 \%$ at one week of age to $45 \%$ as early as one month of age, and then gradually declined to $20-25 \%$ in 6 -month-old infants. The overall exclusive breastfeeding rate in infants $<4$ months was $46 \%(n=246)$. The use of prelacteal feeds $(p<0.0001, n=436)$, not feeding the infant colostrum $(p=0.0008, n=436)$, and Latin ethnicity $(p=0.0091, n=436)$ were associated with a shorter duration of exclusive breastfeeding. Rural mothers were four times more likely to discard the colostrum than urban mothers $(p=0.0110, n=501)$. Actual exclusive breastfeeding duration was shorter than what the mothers reported to be the ideal duration of exclusive breastfeeding for the infant.
\end{abstract}

Conclusions: The rate of exclusive breastfeeding in Bolivian infants fell rapidly during the first months of life. Avoidance of prelacteal feeding and use of colostrum were associated with improved breastfeeding patterns.

\section{Background}

Breastfeeding is associated with a lower incidence of infant diarrhoea and respiratory disease, particularly in less developed countries [1]. A recent ecological study on breastfeeding showed that more than half of all infant deaths from diarrhoeal disease and acute respiratory infections in Latin America are preventable by exclusive breastfeeding in infants aged 0-3 months and partial breastfeeding throughout the remainder of infancy[2]. The theoretical basis for this may be a combination of the nutritional and immunomodulatory effects of human milk[3]. Since 2001, the WHO recommends exclusive breastfeeding up to the age of 6 months (World Health Assembly Resolution 55.25), based largely on work later published by Kramer and Kakuma[4].

In Bolivia, the exclusive breastfeeding rate in infants under 4 months of age has been found to be above $50 \%$, with $14 \%$ of infants still being exclusively breastfed when 6-9 months old[5]. In contrast, a later study in Bolivia 
Table I: Characteristics of Bolivian mothers interviewed about breastfeeding $(n-\max =5$ I 8$)$

\begin{tabular}{|c|c|c|c|}
\hline & $\%$ & $\%$ & $\%$ \\
\hline Social class* & Lower & Middle & Upper \\
\hline$(n=458)$ & 33 & 58 & 9 \\
\hline Civil status & Married & Single & Cohabiting \\
\hline$(n=505)$ & 57 & 9 & 33 \\
\hline Type of work \# & Labourer & White-collar & No work \\
\hline$(n=5 \mid 3)$ & 18 & 10 & 71 \\
\hline Religion & Catholic & Non-Catholic & \\
\hline$(n=515)$ & 76 & 24 & \\
\hline Education & $\leq 5$ years & $>5$ years & \\
\hline$(n=515)$ & 36 & 64 & \\
\hline Place of residence & Urban & Rural & \\
\hline$(n=5 \mid 4)$ & 94 & 6 & \\
\hline Living with infant's father & Yes & No & \\
\hline$(n=507)$ & 85 & 15 & \\
\hline Literacy & Literate & Illiterate & \\
\hline$(n=508)$ & 95 & 5 & \\
\hline Ethnicity & Native & Latin & \\
\hline$(n=456)$ & 58 & 42 & \\
\hline
\end{tabular}

* Social class was assessed by the interviewer on the basis of the mother's answers to the socio-economic questions, her language and appearance, the work of her partner and her area of residence. No weighting was used; instead, social class was based on an overall assessment. \# Five mothers were gainfully employed but there are no data as to their type of work. For that reason, percentages do not add up to I00.

found that no infants were exclusively breastfed at 4 months of age, even if practically all were breastfed at 7 months[6]. Infant nutrition in Bolivia and/or infant and maternal health have been the topic of several studies [711], but none has focused on determinants of breastfeeding.

The main objective of the present study was to describe the breastfeeding pattern in a sample of Bolivian infants as well as the determinants of breastfeeding, including socio-economic, religious and ethnic background. Such data on socio-economic determinants are seemingly lacking, but have elsewhere been proven important[12-14].

Reported breastfeeding duration was also compared with how Bolivian women thought infants should be breastfed. To the author's knowledge, no such comparison has yet been made, and the notion that the actual and the desired durations of exclusive breastfeeding differ has not been substantiated. At the time of the study the recommended duration of exclusive breastfeeding was four to six months[15].

\section{Methods}

\section{Study area}

This study took place in La Paz, Bolivia. The interviews were conducted during a 10-week period in July through September, 1995, at four of the La Paz-El Alto hospitals: Del Nino (Number of infants $=350), 20$ de Octubre $(\mathrm{n}=$ 98), San Gabriel $(\mathrm{n}=46)$ and Obrero $(\mathrm{n}=24)$. The Del
Nino hospital was selected to contribute the majority of infants, as it was the main paediatric hospital in La Paz. At the time of the interviews, there were ten hospitals in La Paz-El Alto, a number of these did however cater mainly to adults. The children at the Del Nino represented all social and ethnic groups, while the 20 de Octubre catered mainly to a native, lower social class population. Residents of the San Gabriel and Obrero hospital catchment areas were more well-to-do than the rest of the population. All mothers visiting one of these hospitals on days when the author was present at the particular hospital were asked to participate in the study.

The sample of infants in this study $(\mathrm{n}=518)$ constituted about $1.3 \%$ of all infants aged one year or younger who lived in the city of La Paz and El Alto in 1995 ( $\mathrm{n}=22671$ +16 579)[16]. According to data from the Bolivian Institute of Statistics, the total numbers of children under five years of age who visited the respective hospitals in 1995 were: Del Nino: 15 420, San Gabriel: 7 713, and 20 De Octubre: $6331[16]$. No data were available for Obrero hospital. The interviews were conducted in waiting halls, consultant rooms and in the maternity wards.

\section{Study population}

Inclusion criteria were: Bolivian mothers with a child aged $\leq 1$ year who came from the La Paz urban area or the villages within a four-hour bus ride from the city. No exclusion criteria were applied. The basis for the selection criterion of "within a four-hour bus ride" was that the 


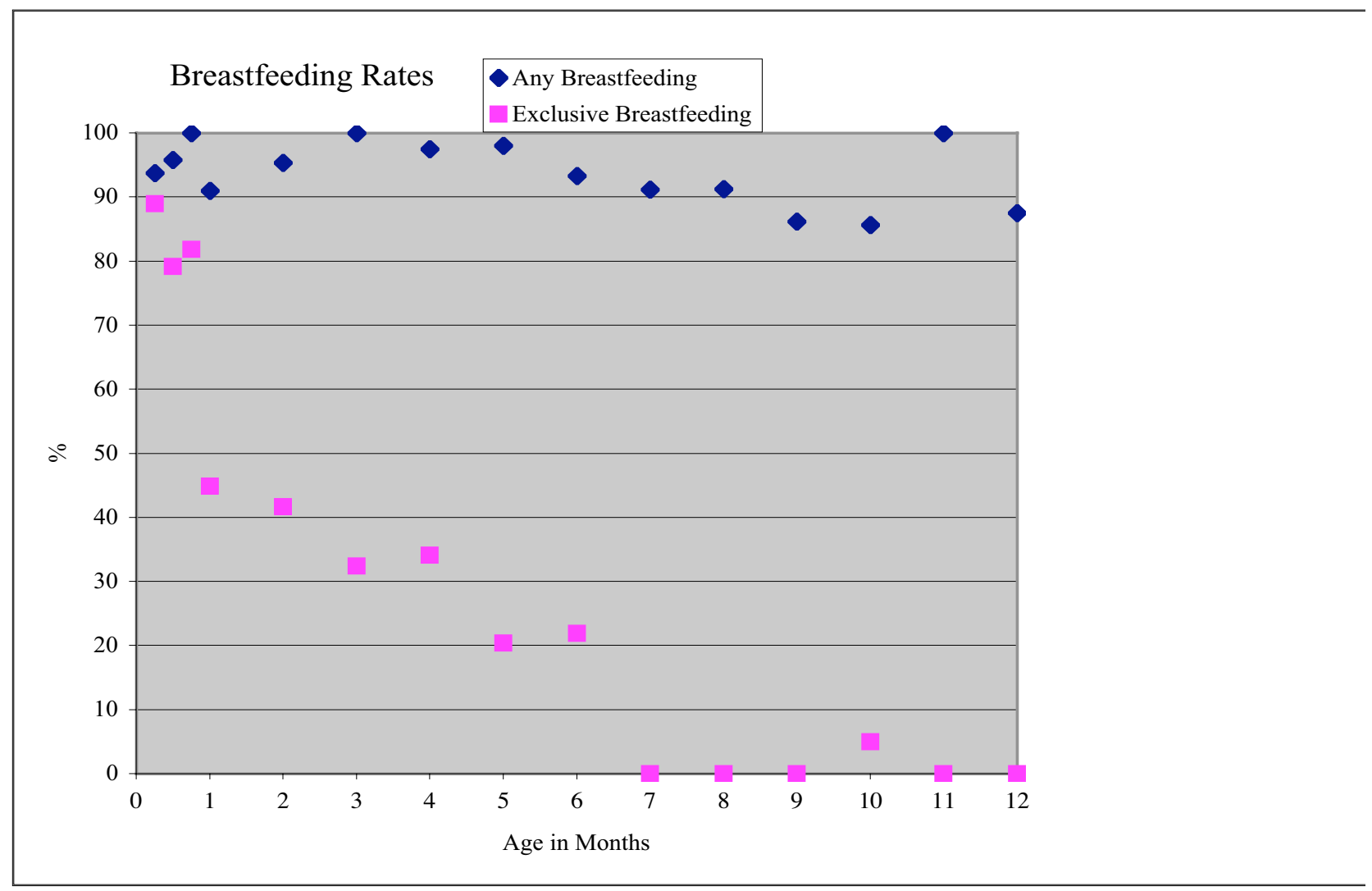

Figure I

Proportions breastfeeding at various ages in the city of La Paz and El Alto (Current Status). Proportions (Ns), according to age in months $(\mathrm{m})$, that received any breastfeeding (exclusive breastfeeding): $\leq 0.25 \mathrm{months:} 76 / 81$ (73/82); $0.5 \mathrm{~m}$ : 23/24 (I9/24); 0.75 m: I I/II (9/II); I m: $45 / 49$ (22/49); 2 m: $42 / 44$ (I8/43) 3 m: 38/38 (I2/37); 4 m: $39 / 40$ (I4/4I); 5 m: $48 / 49$

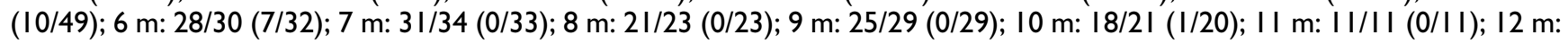
$21 / 24(0 / 24)$

three communities of Copacabana, Sorata and Coroico were all within a four-hour bus ride from La Paz. Both mothers of well children and of sick children were interviewed. The presence of illness in the child was not recorded in the questionnaire. Out of 528 mothers, 518 agreed to participate. The 10 who declined to participate did so mainly because they did not speak Spanish. The interviewed mothers were between 13 and 45 years of age ( $\mathrm{n}=512$, mean $25.6 \pm 5.9$ (SD) years), and a total of 72 were teenagers. Practically all the mothers were urban dwellers and the majority (76\%) were Catholic (Table 1$)$. Just over half were native women, and the rest were of Latin origin. In this study, Latin ethnicity means largely of European ancestry, while native ethnicity refers to those of indigenous origin. A number of women were of mixed origin; they were nevertheless classified as either Latin or
Native. Compared to women of native origin, Latin women more often had five years of education ( $88.5 \%$ vs. $46 \%$; $<0.0001$ ), and were literate (99\% vs. $91 \%$; $\mathrm{p}=$ 0.004 ). However, gainful employment (Latin: 30\% vs. native: $28 \% ; \mathrm{p}=0.161$ ) and urban origin (Latin: $97 \%$ vs. native: $95 \%$; $\mathrm{p}=0.2111$ ) were equally common.

The average age of the infants was $4.2 \pm 3.6$ (SD) months (median 4 months). One hundred and sixty-eight infants were $\leq 1$ month of age, 21 were 10 months old, 11 were 11 months old and 24 were 12 months old (see legends to Figures 1 and 2 for complete data on age distribution of the infants). 


\section{Interviews}

The interviews were conducted using a structured questionnaire. All subjects were interviewed in Spanish by the author. No interpreter was used.

Some interviews were interrupted by the consulting doctor, and therefore some of the questionnaires were not fully completed. All the socio-economic data are based on at least 500 of the 518 respondents except for ethnicity (n $=456)$ and social class $(\mathrm{n}=458)$. The numbers in each calculation may be smaller than 500 because of missing values in other categories. The following number of motherinfant pairs were analysed in the univariate analyses: prelacteal feeds and colostrum ( $\mathrm{n}=494-518$ motherinfant pairs), perception of optimal breastfeeding duration ( $\mathrm{n}=455-487)$, number of breastfeeds per 24 hours ( $\mathrm{n}=449-455)$, and nighttime breastfeeding frequency ( $\mathrm{n}$ = 388-435). Univariate statistics for breastfeeding patterns in previous infants were based on 221 mother-infant pairs or 383 children (some mothers had more than one previous child)

\section{Definitions}

Exclusive breastfeeding was defined as not giving anything other than breast milk at the time of the interview. In this definition of exclusive breastfeeding, the maximum allowable intake of non-breast milk fluid in the past week was set at 3 cucharillas (teaspoons) or 1 cuchara (larger spoon) or $1 / 2$ fluid ounce. Except for this amount of fluid and for prelacteal feed, the absence of previous complementary foods (or supplementary fluids totalling more than the above weekly amount) since birth was demanded as proof of exclusive breastfeeding. In those cases where the weekly intake of food/fluid could not be specified, the end of exclusive breastfeeding was set at the date of introduction of the food/fluid in question. The provision of vitamins did not preclude exclusive breastfeeding. Hence the definition of exclusive breastfeeding used in this study differs from that suggested by Labbok et al[17]. In all analyses of exclusive breastfeeding in the current paper, a "since birth" perspective has been used. "Any breastfeeding" included exclusive, predominant and partial breastfeeding[17].

Colostrum was defined as the breast milk produced in the first five days after delivery, prelacteal feed as food/liquid given to the infant before initiating breastfeeding for the first time, and nighttime feeding as feeds between 10 p.m. and 6.00 a.m. The mothers were asked how many times they had breastfed their child over a 24-hour period during the last week before the interview (an average number was recorded). When defining a breastfeed, no minimal duration was required. However, at least 30 minutes did have to elapse between two feeds for them to be considered as separate feeds. On-demand feeding was defined as the mother breastfeeding solely according to the needs of the infant.

\section{Ethics}

The study design was presented to the directors of the four hospitals, who were also briefed on the contents and objectives of the study, after which permission to carry out the study was granted. All women who took part in the study gave their informed consent.

\section{Statistical analyses}

The significance level was set at $\mathrm{p}<0.05$ (two-tailed analysis), except in the ANOVA post hoc analysis, where the number of comparisons was used to set the significance level (Bonferroni correction: $\mathrm{p}<0.05 / \mathrm{n}$-number of comparisons.[18]).

Due to a sample size under 1000, only two signficance figures have been used when reporting percentages.

Data concerning breastfeeding rates in infant groups spanning more than one month have been pooled according to the size of each group. However, the numbers reported reflect the actual number of cases. The numbers (n) accompanying the p-values equal the numbers of mothers/infants in all subgroups being compared in the calculation in question. StatView 5.0 (SAS Institute Inc., Cary, NC, USA) was used for the calculations.

\section{Univariate analyses}

Continuous variables were plotted against a normal distribution curve. With the exception of number of breastfeeds per 24 hours and number of breastfeeds during the nighttime, all continuous variables were deemed normally distributed (normal distribution in the two non-parametric variables was also rejected using the Kolmogorov-Smirnov 1-sample test)[19]. Normally distributed variables were tested using Student's t-test, or ANOVA. Proportions were compared using the Pearson Chi-square test. Determinants of breastfeeding frequency were analysed using the Mann-Whitney U-test or the Kruskal-Wallis test (p-values corrected for ties are presented). Kaplan-Meier curves were used to establish the median duration of exclusive breastfeeding[20].

\section{Multivariate analyses}

The following main outcome measures and dependent variables were analysed using regression analyses: use of prelacteal feed, intake of colostrum, exclusive breastfeeding duration, duration of any breastfeeding [in the previous child], on-demand feeding, and desired exclusive breastfeeding duration. The aim was to identify environmental and socio-economic factors of importance to the dependent variables. 


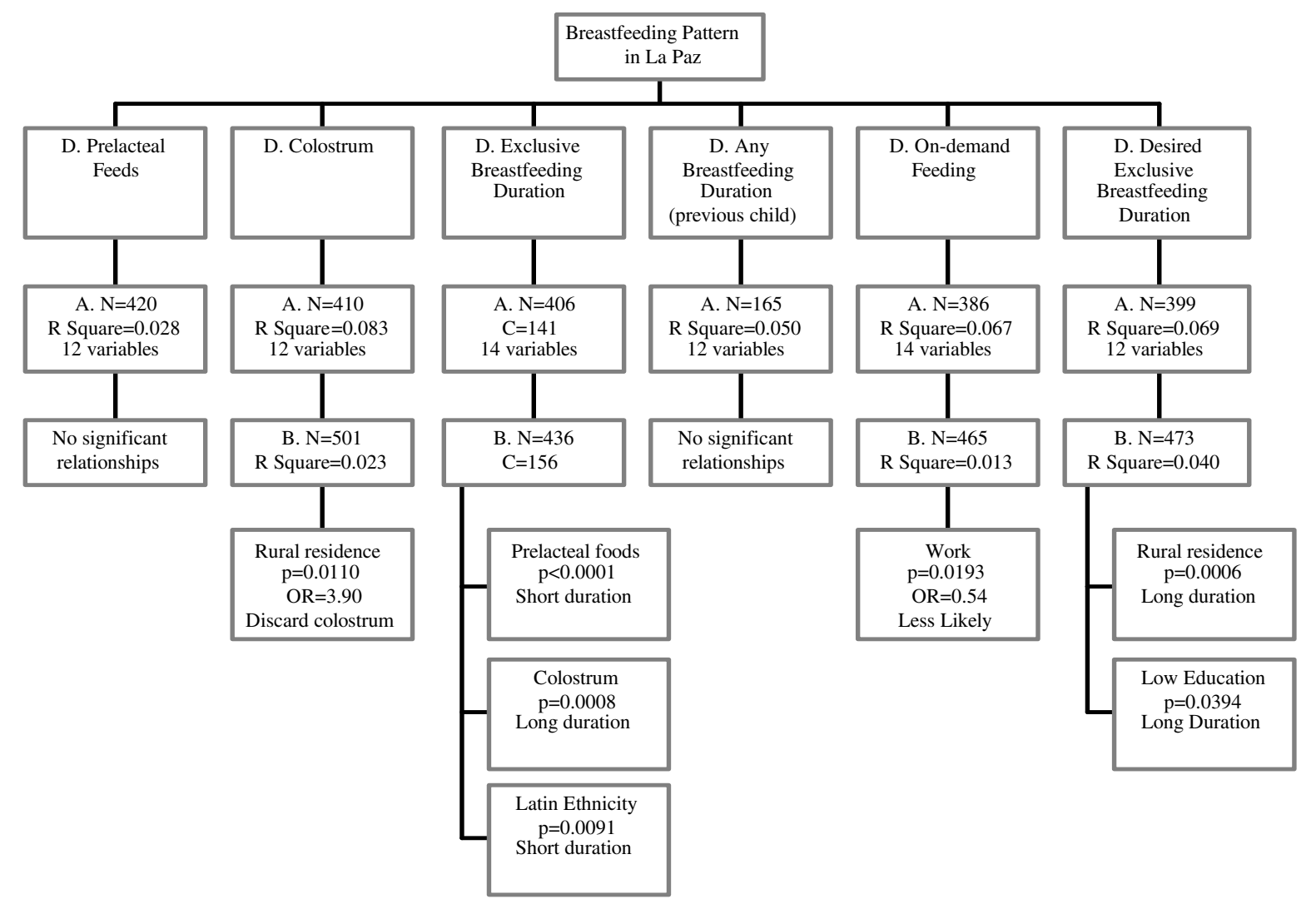

Figure 2

Results of regression analyses of breastfeeding pattern in La Paz.Figure 2 is an overview of independent factors associated with a number of dependent variables in the present study. For example, a stepwise backward logistic regression analysis of giving colostrum (initial analysis included 410 subjects and 12 independent variables) revealed that rural residence was associated with an odds ratio of 3.90 for discarding colostrum $(p=0.0110)$ (Final analysis of rural residence vs. giving colostrum was based on $50 \mathrm{I}$ subjects. Rural residence explained 0.0203 of the total variation in giving colostrum.) $A=$ Initial regression model. $\mathrm{B}=$ Final regression model. $\mathrm{C}=$ Censored value. $\mathrm{D}=$ Dependent variable in the regression analysis. OR $=$ Odds Ratio. Work = Gainful employment.

For that purpose, multiple linear regression was used to analyse continuous variables, logistic regression was used for proportions, and Cox's regression for the duration of exclusive breastfeeding[19]. The number of censored observations is given in the text or in Figure 2.

Kaplan-Meier curves were also used to evaluate the relationship between exclusive breastfeeding duration and socioeconomic determinants, since Cox's regression may fail to detect clinically important, but statistically insignificant, relationships[19].
Cox's regression and Kaplan-Meier curves are so called survival analyses. Survival analyses are often used when the variable of interest is the length of time that elapses before a certain event occurs. This event may be death, but it may also be the "end" of a particular condition. In the current paper, introduction of complementary feeding terminated exclusive breastfeeding, and is therefore regarded as "death". Data on exclusive breastfeeding duration in children who had already been introduced to complementary foods/fluids at the time of the interview were classified as uncensored, as opposed to censored data in children who were still exclusively breastfed. 
Table 2: Initial and final regression models for risk of short duration of exclusive breastfeeding

\begin{tabular}{|c|c|c|c|c|}
\hline Initial Model & Coeff. & Hazard Ratio & 95\% Cl Hazard Ratio & P-value \\
\hline Prelacteal feed given & 0.746 & 2.11 & $1.53-2.90$ & $<0.0001$ \\
\hline Colostrum given & -1.032 & 0.36 & $0.2 \mathrm{I}-0.6 \mathrm{I}$ & 0.0002 \\
\hline Latin Ethnicity & 0.310 & 1.37 & $1.01-1.85$ & 0.0404 \\
\hline Catholic & 0.322 & 1.35 & $0.98-1.85$ & 0.0693 \\
\hline Urban Living & 0.611 & 1.84 & $0.92-3.68$ & 0.0833 \\
\hline Gainful employment & 0.219 & 1.24 & $0.94-1.64$ & 0.1217 \\
\hline Cohabitant & -0.240 & 0.78 & $0.55-1.12$ & 0.1856 \\
\hline Sex. Male infant & 0.146 & 1.16 & $0.90-1.48$ & 0.2461 \\
\hline Education $\leq 5$ years & 0.157 & 1.17 & $0.85-1.61$ & 0.3386 \\
\hline Hospital. Del Nino & -0.081 & 0.92 & $0.69-1.22$ & 0.5761 \\
\hline Literacy & -0.590 & 0.94 & $0.54-1.66$ & 0.8384 \\
\hline Upper social class & -0.023 & 0.98 & $0.65-1.47$ & 0.9124 \\
\hline Final Model & Coeff. & Hazard Ratio & 95\% Cl Hazard Ratio & P-value \\
\hline Prelacteal feed given & 0.808 & 2.24 & $1.66-3.03$ & $<0.0001$ \\
\hline Colostrum given & -0.881 & 0.41 & $0.25-0.69$ & 0.0008 \\
\hline Latin Ethnicity & 0.317 & 1.37 & I.09-1.75 & 0.0091 \\
\hline
\end{tabular}

Coeff. $=$ Coefficient $\mathrm{Cl}=$ Confidence interval Hazard ratios $>1$ indicate shorter exclusive breastfeeding duration. After stepwise backward regression, three variables remain ("Final model") associated with exclusive breastfeeding duration $(p<0.05)$.

A backward stepwise mode was used in order to avoid dropping non-significant variables that affected the model fitness. In no analysis did the number of independent variables exceed $\mathrm{n} / 10$ variables (according to recommendations by Altman[21]).

\section{Independent variables}

Univariate analyses were carried out against the following variables: sex of the infant, hospital, age of the mother, urban/rural residence, religious affiliation, social class, ethnicity, literacy, educational level, gainful employment (work), living with the infant's father, and breastfeeding of previous infant. All multivariate analyses initially included the above-mentioned independent variables. Giving colostrum and feeding the child prelacteal feeds were included among the independent variables in the multivariate analyses of on-demand feeding and exclusive breastfeeding duration.

Dichotomous categorisation of the independent variables was performed in order to carry out logistic regression analyses. Infants from the Del Nino Hospital $(\mathrm{n}=350)$ were compared with infants from the other hospitals $(\mathrm{n}=$ 168 ). Mothers were divided into two groups according to median age ( $<25 \mathrm{yr}$. vs. $\geq 25 \mathrm{yr}$.). More than five years of education was regarded as "high education" (vs. low education). Religious affiliation $(\mathrm{n}=515)$ was categorised as Catholic $(\mathrm{n}=394)$, or non-Catholic $(121$; including 31 Protestants and 67 atheists). Social class was assessed by the interviewer on the basis of the mother's answers to the socio-economic questions, her language and appearance, the work of her partner and her area of residence. No weighting was used; instead, social class was based on an overall assessment. In cases of uncertainty the mother in question was classified as being of middle class. For purposes of the logistic regression analyses, lower class and middle class mothers were collapsed into one category and then compared with upper class mothers. Mothers who were cohabiting or were married were collapsed into one category before comparisons were made with single mothers in the logistic regression analyses. Mothers who failed to read a sentence out loud in Spanish (from daily life) were classified as illiterate. Work was defined as gainful employment yielding an income (on a regular basis). Mothers were not asked to specify the duration of work.

\section{Results}

\section{Exclusive breastfeeding}

The time pattern of exclusive breastfeeding could be split into four phases: about $75-85 \%$ of the infants under 3 weeks of age were exclusively breastfed, and during the following 1-2 months about $40 \%$ of the infants were exclusively breastfed (Figure 1). The rate of exclusive breastfeeding then gradually declined, reaching 20-25\% among 6-month-old infants. Except for one 10-monthold infant, no infants were exclusively breastfed after 6 months of age. The exclusive breastfeeding rate in infants under 4 months of age was $46 \%(n=246$, percentages were adjusted for the sizes of the age sub-groups).

The median duration of exclusive breastfeeding was 3 months $(n=508)$ (Kaplan-Meier survival curve). Short exclusive breastfeeding duration correlated with the use of prelacteal feeds $(\mathrm{p}<0.0001)$, not giving the infant colos- 
trum ( $\mathrm{p}=0.0008)$, and the mother being of Latin ethnicity $(\mathrm{p}=0.0091)$ (Cox's regression analysis) (Figure 2 and Table 2).

\section{Prelacteal feeds and use of colostrum}

Prelacteal feed had been given to 88/518 infants (17\%): formula to 54 , tea to 27 , honey to 1 , salt to 1 , other types of drink to 1 , and a special diet because of illness to 4 . No data were recorded as to the amount of prelacteal feed given.

Use of prelacteal feed did not correlate with any of the independent variables in the model used in this study. There was, however, a trend for illiteracy to correlate with the use of prelacteal feed $(\mathrm{p}=0.0643)$ (multivariate analysis). Restricting the analyses to the use of non-formula prelacteal feed revealed a positive correlation with illiteracy (univariate analysis, $\mathrm{p}=0.0068$ ).

Nearly all infants had received colostrum $(94 \%, \mathrm{n}=475 /$ 504). Giving colostrum did not differ among the 88 infants who had been fed different types of prelacteal feeds (tea, formula, honey, salt and other food).

Rural mothers were more prone to discard the colostrum (Logistic regression analysis: $\mathrm{OR}=3.90 ; 95 \% \mathrm{CI}$ OR $=$ 1.36-11.1; $\mathrm{p}=0.0110$; univariate analysis: $\mathrm{p}=0.0065$ ) (Figure 2).

\section{Any breastfeeding}

The rate of any breastfeeding, irrespective of the use of complementary food or formula, remained high during the first year (Figure 1). Ninety-eight percent of the infants had been breastfed for some amount of time. All 3month-old infants were breastfed, as were $93 \%$ of the infants aged 6 months and $87 \%$ of those aged one year. Among infants below the age of 4 months, 96\% were breastfed ( $n=247$, percentages were adjusted for the sizes of the age sub-groups).

The average duration of any breastfeeding in the mothers' previous children was (months $\pm \mathrm{SD}$ ): All children: $16.8 \pm$ $8.2,1^{\text {st }}$ child $17.1 \pm 8.9,2^{\text {nd }} 15.9 \pm 7.1,3^{\text {rd }} 17.6 \pm 8.2,4^{\text {th }}$ $15.8 \pm 4.4$ and $5^{\text {th }}$ child $17.0 \pm 4.2$. Duration of any breastfeeding did not correlate with birth order.

Neither socio-economic nor bio-cultural factors were associated with the duration of breastfeeding in the previous infant (Linear regression analysis) (Figure 2).

\section{Diurnal breastfeeding pattern}

The number of breastfeeds per 24 hours was relatively constant during the first year (data represent median and $1^{\text {st }}$ and $3^{\text {rd }}$ quartiles; quartiles in parentheses): 1 month (mo) of age: $8.5(6,11)$; 3 mo: $7(6,10)$; 6 mo: $7(6,8)$, and 12 mo: $6(4,8)$ (Figure 3). The median number of nighttime breastfeeds remained around 2 throughout the first year of life, although in some age groups it reached 3 nighttime breastfeeds.

\section{On-demand feeding}

A majority of the mothers breastfed on-demand (84\%). This feeding mode was less common in mothers with gainful employment $(\mathrm{OR}=0.54,95 \% \mathrm{CI}=0.32-0.91)$ (Multivariate analysis) (Figure 2).

\section{Perception of optimal breastfeeding duration}

Out of 479 mothers, 337 (70\%) considered the age of 4 (n $=42), 5(n=47)$ or 6 months $(n=248)$ to be the best time to stop exclusive breastfeeding from the infant's perspective.

Univariate analyses showed that rural women felt that infants should be exclusively breastfed for a longer time ( $p$ $<0.0001$ ) (Table 3 ). This was also true for women with less than six years of education $(\mathrm{p}=0.0062)$. Multivariate analyses were similar: rural women $(\mathrm{p}=0.0006)$ and women with less than six years of education $(\mathrm{p}=0.0394)$ (Figure 2).

In women with more than five years of education, $76 \%$ stated that 4-6 months was the best duration of exclusive breastfeeding as compared with $60 \%$ of women with a lower educational level $(p=0.0002)$. Latin women were more inclined to say that 4-6 months was the best time to stop exclusive breastfeeding $(\mathrm{p}=0.0160)$. In a logistic regression including both educational level and ethnicity as independent variables, only high educational level (OR $=1.81 ; 95 \% \mathrm{CI} O R=1.13-2.91 ; \mathrm{p}=0.0134)$ remained significantly associated with the perception that infants should be exclusively breastfed for 4-6 months.

Mothers indicating 4-6 months as the best duration of exclusive breastfeeding did not differ from other mothers in actual duration of exclusive breastfeeding $(\mathrm{p}=0.2207$; censored 168/469). Mothers indicating 6 months or more as the best duration of exclusive breastfeeding reported a more extended duration of actual exclusive breastfeeding ( $p=0.0080$; censored 168/469).

When asked for their opinion on the ideal duration of any breastfeeding, most mothers answered 12-24 months $(85 \%)$. Illiterate mothers, mothers with less than six years of education, mothers with manual rather than white-collar work, and mothers who had breastfed earlier infants expressed a desire to sustain breastfeeding longer than their counterparts did (univariate analyses; all p-values $<0.05)$. 


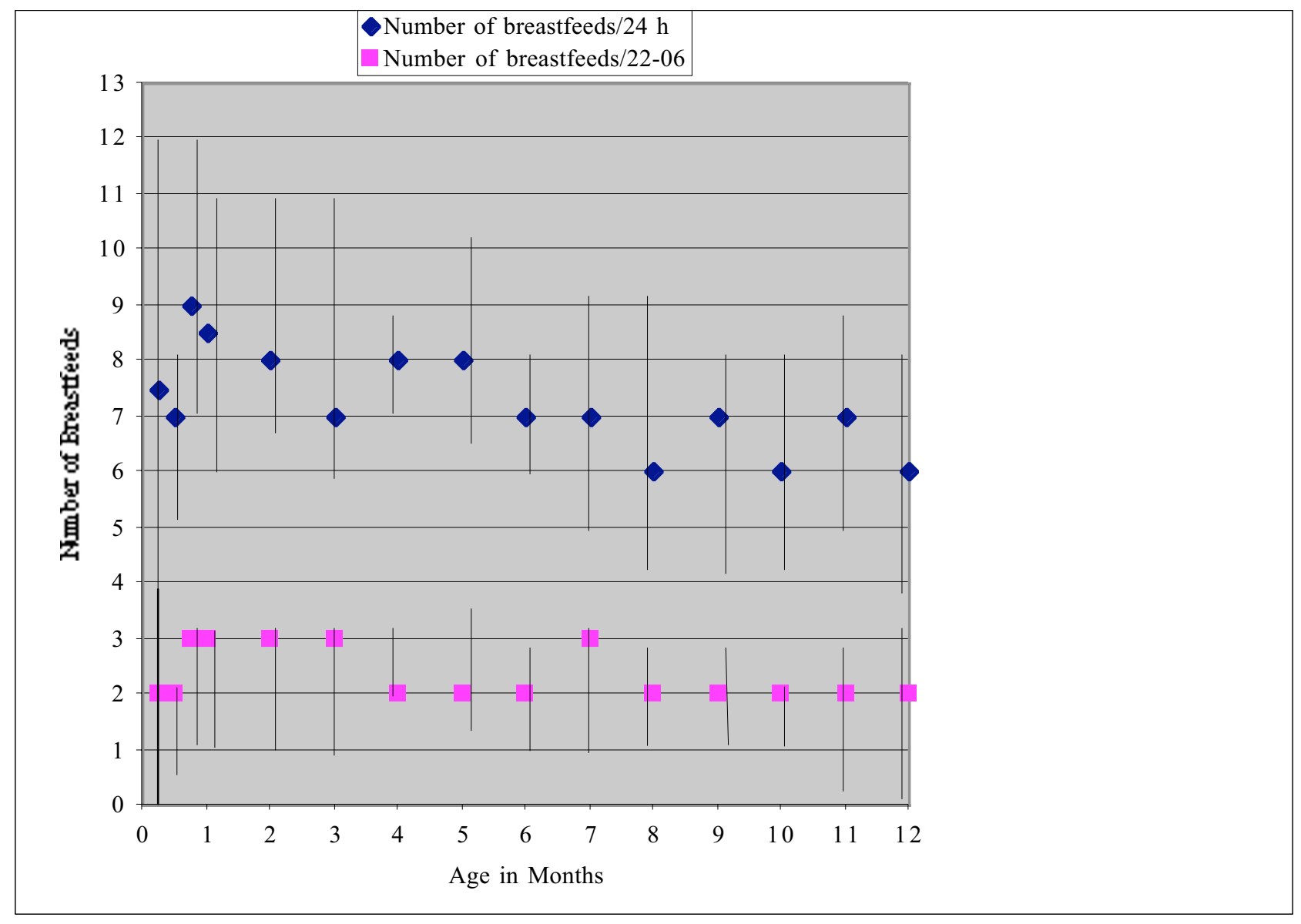

\section{Figure 3}

Breastfeeding frequency per 24 hours and during the nighttime (22-06) in La Paz (current status).Data are given as median number of breastfeeds, with whiskers indicating 25-75 percentiles. Number of infants used for calculations of number of breastfeeds/24 hours at various ages in months (nighttime (22-06: 10 pm-6 am)): $\leq 0.25$ month: 50 (4I); 0.5 m: 21 (2I); 0.75 m: II (I I); I m: 46 (46); 2 m: 37 (37); 3 m: 36 (35); 4 m: 39 (38); 5 m: 48 (48); 6 m: 27 (27); 7 m: 33 (33); 8 m: 23 (23); 9 m: 28 (28); 10 m: 29 (29); I I m: II (I I); 12 m: 22 (22). For the age-group $\leq 0.25$ months, only mother-infant pairs where the mother was deemed to have established a regular breastfeeding pattern were included in the analyses.

\section{Discussion}

The purpose of this study was to describe the breastfeeding pattern in a sample of Bolivian infants. The results suggest that the rate of exclusive breastfeeding was initially high but then rapidly declined. Use of prelacteal feeds, not feeding the infant colostrum and Latin ethnicity were associated with a shorter duration of exclusive breastfeeding.

\section{Strengths and limitations}

To the author's knowledge, the present study is the first to examine socio-economic and biological determinants of the breastfeeding pattern in Bolivia. It also presents data on the diurnal breastfeeding pattern in a less developed country and links actual breastfeeding behaviour with that perceived by the mother as optimal for the infant. The use of only one interviewer increased the consistency of interview management and interpretation of the mothers' answers.

In the current study, the definition of exclusive breastfeeding allowed for prelacteal feed. Prelacteal feed was not an exclusion criterion in the WHO definition of exclusive breastfeeding at the time, in which the absence of food other than breast milk, drops and syrups is required during the 24 hours preceding the enquiry (page 2, http:// 
Table 3: Feeding patterns in rural vs. urban mothers

\begin{tabular}{|c|c|c|c|}
\hline & \multicolumn{3}{|c|}{$95 \% \mathrm{Cl}$} \\
\hline & Odds Ratio & Odds Ratio & P-value \\
\hline Discard Colostrum & 3.90 & $1.36-11.08$ & 0.0110 \\
\hline Prelacteal feed, given & 1.96 & $0.84-4.58$ & 0.1210 \\
\hline Prelacteal feed without formula, given & 1.08 & $0.25-4.77$ & 0.9142 \\
\hline On-demand feeding & 2.31 & $0.53-9.99$ & 0.2628 \\
\hline \multirow[t]{3}{*}{ Exclusive breastfeeding* } & 0.68 & $0.4 I-1.12$ & 0.1450 \\
\hline & & $95 \% \mathrm{Cl}$ & \\
\hline & Difference (months) & Difference (months) & \\
\hline Duration of any breastfeeding in previous infant & -0.90 & $-5.05 ; 3.24$ & 0.6685 \\
\hline Desired duration of any breastfeeding & -0.53 & $-3.18 ; 2.13$ & 0.6978 \\
\hline Desired duration of exclusive breastfeeding & 3.79 & $2.28 ; 5.66$ & $<0.0001$ \\
\hline
\end{tabular}

$\mathrm{Cl}=$ Confidence Interval $*$ Censored (I84/505 participants)

www.who.int/child-adolescent-health/ New Publications/NUTRITION/ who cdd ser 91.14.PDF). With that exception, the rate of exclusive breastfeeding in this study was based on information on the current status and the absence of complementary foods (including milks and other fluids) at any time prior to the present interview. It has recently been shown that data based on current status differ from data based on daily records of feeding[22], and that longterm recall provides lower estimates of the prevalence of exclusive breastfeeding in infants under 8 months of age when compared to one 24 -h recall in cross-sectional studies such as Demographic and Health Surveys[23]. Different recall methods may be one reason why the data in this study differ from those of McCann et al.[5,24], with lower rates of exclusive breastfeeding among infants below 4 months of age in the present study than in theirs $(46 \%$ vs. $58 \%$ ). Moreover, most of the infants in this study were of urban origin. This also restricts the possibility of extrapolating the descriptive findings to populations where many inhabitants live in the rural areas, although data on exclusive breastfeeding from the present study correlate well with data from the whole of Bolivia (data from Bolivian Demographic and Health Enquiry)[16] (Exclusively breastfed: infants $\leq 1$ month: $61 \%$ (JFL: 64); 2-3 months: 48\% (JFL: 37$)$; 4-5 months: $27 \%$ (JFL: 27); 6-7 months: 5.2\% (JFL: 11 ); 8-9 months: $2.8 \%$ (JFL: 0); and 10-11 months: 0\% (JFL: 3.1). (Data from the present study (JFL) were pooled for the purpose of this comparison.). Data in this study may also differ from those of McCann et al.[5], since data were obtained in different years.

This is a cross-sectional and retrospective study; hence no conclusions should be drawn regarding causal relationships. Nevertheless, some of the findings in this study (such as the negative association between use of prelacteal feeds and duration of exclusive breastfeeding) merit fur- ther research, and if verified, they could have important implications.

One possible drawback to the study is that both healthy and sick infants were included. There are no data on whether the infants in this study visited one of the study hospitals in order to receive an immunisation, to attend the well-baby clinic, or to seek assistance due to illness. Although vaccination coverage was around $80 \%$ in Bolivia in the mid-1990s and only some 7\% of infants in urban areas never received any vaccinations [16], there is a risk that the reasons for some visits were associated with their feeding pattern[25]. The risk of bias may be especially great among the older infants, who may have more frequently been brought to the hospital because of illness (and thus, for example, were possibly less likely to be breast-fed). Many of the younger infants were still exclusively breastfed at the time of interview. That was not the case for older infants. This could increase the risk of bias, since the values entered in Cox's regression of actual exclusive breastfeeding duration were more often censored in younger infants than in older infants. More importantly, this sample may not accurately reflect the situation in La Paz as a whole, because it excluded mothers who did not bring their children to the clinics. Illness in the child may also have worried the mother. That could have affected the reliability of her answers.

A number of interviews were interrupted. This caused incomplete data sets. For that reason crude data and actual numbers have, to a large extent, been presented in the present article. Interviews were interrupted at all hospitals and in all social classes, and hence there is little reason to believe that the interruptions would have caused any of the observed associations; it may rather be the case that they blurred the results. 
This is an exploratory study where results are data driven rather than conceptually driven. The purpose of the current study was to explore possible determinants of breastfeeding duration, and to do that the stepwise backward regression approach was deemed appropriate. Due to the large number of tests, there is a risk that some statistical significance, particularly those close to $\mathrm{p}=0.05$, are due to random error rather than representing true findings.

\section{Main findings}

The rate of exclusive breastfeeding was initially very high, but then declined rapidly during the second month. This is reminiscent of similar patterns seen in Mexico, Brazil and Honduras[13]. The radical decline is most unfortunate, keeping in mind that the WHO recently decided to change the recommended duration of exclusive breastfeeding from 4-6 months to 6 months[26].

In contrast, the rate of any breastfeeding was very high in infants under 1 year of age, and in no age sub-group was it below $85 \%$. This is a very high level compared with reports from Mexico.[27] and neighbouring Brazil[28], but it is in line with the high prevalence of any breastfeeding at 7 months in the Simondon et al. study from Bolivia[6], and data from the Bolivian Demographic and Health Enquiry (97\% out of 1115 La Paz women had breastfed their last child.[29]). In the present study there was no correlation between a range of socio-economic and cultural factors and the duration of any breastfeeding in the previous child. One reason for this may be that the rates of any breastfeeding are equally high in women from all socio-economic strata in the study area. These findings are in contrast to reports from other parts of the world indicating a significant correlation between breastfeeding duration and socio-economic conditions[12,30,31]. Alternative explanations may be the moderate sample size in the current study or lack of accuracy in recalled duration of any breastfeeding. There is also a risk that the assessment used in the current study does not mirror the actual economic situation of the household.

Consumption of prelacteal feeds was strongly inversely related to the duration of exclusive breastfeeding. These findings confirm the report of Perez-Escamilla et al[32], where both milk-based prelacteal feeds and prelacteal water were negatively associated with exclusive breastfeeding ( $\mathrm{OR}=0.18$ and 0.19 , respectively). Similar data have also been presented for Mexico[33]. The linkage between prelacteal feeds and short duration of exclusive breastfeeding has strong implications. In the present study a relatively small percentage of the infants had been given prelacteal feeds compared with the results obtained for rural Bolivia by McCann and Bender.[11]. One reason for this discrepancy may be the rather restrictive definition of prelacteal feed used in the present study. Whether prelacteal feeds are given before the very first breastfeed or between the second and third breastfeed is probably irrelevant regarding its impact on infant feeding patterns. It is, however, evident that more knowledge is needed regarding the circumstances surrounding the use of prelacteal feeds. The problem of prelacteal feeds must be confronted.

The discrepancy between actual exclusive breastfeeding behaviour and the perception of how long the infant should be exclusively breastfed is striking. Regardless of the underlying mechanisms, this discrepancy indicates a potential for increasing the rates of exclusive breastfeeding once the mothers' underlying beliefs in this regard have been systematically elucidated. To the author's knowledge, this issue has not been studied previously. Active promotion of breastfeeding may increase both any and exclusive breastfeeding rates, with resulting effects on the risk of diarrhoea, among other things[34]. The author believes that efforts to inform expectant and breastfeeding mothers are important means for improving infant health both in Bolivia and elsewhere. It has recently been shown that extra professional support is beneficial for both any breastfeeding and exclusive breastfeeding[35]. All such strategies should also include the discouragement of prelacteal feeds (without this action being culturally offensive) and encouragement to feed infants colostrum.

\section{Conclusions}

The present study showed a rapid decrease in exclusive breastfeeding rates in Bolivian infants during the first months of life. There was also a discrepancy between the actual and the desired duration of exclusive breastfeeding. Both avoidance of prelacteal feeding and use of colostrum seem to be associated with improved breastfeeding patterns. This is, however, a cross-sectional and retrospective study with a risk of recall bias. Prospective studies are needed to confirm the results of this study.

\section{List of abbreviations used}

$\mathrm{CI}=$ Confidence interval

OR $=$ Odds ratio

$\mathrm{SD}=$ Standard deviation

$\mathrm{SE}=$ Standard error (only used in Table 2)

Coeff. = Coefficient (only used in Table 2)

\section{Competing interests}

None declared.

\section{Authors' contributions}

JFL is the sole author of this paper. 


\section{Acknowledgements}

This study was partly supported by the Swedish International Development Authority.

Sven-Arne Silfverdal is acknowledged for his constructive advice.

\section{References}

I. WHO: Effect of breastfeeding on infant and child mortality due to infectious diseases in less developed countries: a pooled analysis. Lancet 2000, 355:45 I-455.

2. Betran AP, de Onis M, Lauer JA and Villar J: Ecological study of effect of breast feeding on infant mortality in Latin America Bmj 200I, 323:303-306.

3. Hanson LA: The mother-offspring dyad and the immune system Acta Paediatr 2000, 89:252-258.

4. Kramer MS and Kakuma R: Optimal duration of exclusive breastfeeding Cochrane Database Syst Rev 2002, I:CD0035 I 17.

5. McCann MF, Bender DE and Rangel-Sharpless MC: Infant feeding in Bolivia: a critique of the World Health Organization indicators applied to demographic and health survey data Int J Epidemiol 1994, 23:129-137.

6. Simondon KB, Gartner A, Berger J, Cornu A, Massamba JP, San Miguel JL, Ly C, Missotte I, Simondon F, Traissac P, Delpeuch F and Maire B: Effect of early, short-term supplementation on weight and linear growth of 4-7-mo-old infants in developing countries: a four-country randomized trial Am J Clin Nutr 1996, 64:537-545.

7. Forste R: Infant feeding practices and child health in Bolivia J Biosoc Sci 1998, 30:107-125.

8. Novotny $R$ and Haas JD: Maternal anthropometry and infant growth with exclusive breast feeding in La Paz, Bolivia J Trop Pediatr 1987, 33:309-314.

9. Bender DE, Rivera T and Madonna D: Rural origin as a risk factor for maternal and child health in periurban Bolivia Soc Sci Med 1993, 37:1345-1349.

10. Bender DE and McCann MF: The influence of maternal intergenerational education on health behaviors of women in periurban Bolivia Soc Sci Med 2000, 50: I I89-II96.

II. McCann MF and Bender DE: Maternal and infant feeding practices in rural Bolivia Bull Pan Am Health Organ 1992, 26: I 48-I 56.

12. Sjölin S, Hofvander $Y$ and Hillervik C: Factors related to early termination of breast feeding Acta Paediatr Scand 1977, 66:505-5 I I.

13. Perez-Escamilla R, Lutter C, Segall AM, Rivera A, Trevino-Siller S and Sanghvi $T$ : Exclusive breast-feeding duration is associated with attitudinal, socioeconomic and biocultural determinants in three Latin American countries J Nutr 1995, I 25:2972-2984.

14. Hornell A, Aarts C, Kylberg E, Hofvander $Y$ and Gebre-Medhin M: Breastfeeding patterns in exclusively breastfed infants: a longitudinal prospective study in Uppsala, Sweden Acta Paediatr |999, 88:203-2। |.

15. WHO/UNICEF: Innocenti declaration on the protection, promotion and support of breastfeeding. Ecology of Food and Nutrition 1991, 26:271-273.

16. Instituto Nacional de Estadistica - República de Bolivia.: Información Estadistica 1995 La Paz, Instituto Nacional de Estadistica (INE) - República de Bolivia.; 1995.

17. Labbok $M$ and Krasovec K: Toward consistency in breastfeeding definitions Stud Fam Plann 1990, 2 1:226-230.

18. Hassard TH: Understanding biostatistics. St. Louis, Missouri, USA, Mosby Year Book; 1991.

19. Armitage P, Berry G and Matthews JNS: Statistical Methods in Medical Research 4thth edition. Oxford, Blackwell Science Ltd; 2002.

20. Bland JM and Altman DG: Survival probabilities (the KaplanMeier method) BMJ 1998, 317:1572.

21. Altman DG: Practical statistics for medical research. London, Chapman and Hall; 1991.

22. Aarts C, Kylberg E, Hornell A, Hofvander Y, Gebre-Medhin M and Greiner T: How exclusive is exclusive breastfeeding? A comparison of data since birth with current status data Int J Epidemiol 2000, 29: 104I-1046.

23. Piwoz EG, Creed de Kanashiro H, Lopez de Romana G, Black RE and Brown KH: Potential for misclassification of infants' usual feeding practices using 24-hour dietary assessment methods J Nutr 1995, I 25:57-65.
24. Willett W: Nutritional Epidemiology Monographs in Epidemiology and Biostatistics Volume 30. 2nd edition. Oxford, Oxford University Press; 1998.

25. Bauchner $H$, Leventhal JM and Shapiro ED: Studies of breast-feeding and infections. How good is the evidence? Jama 1986, 256:887-892.

26. WHO: World Health Organization. Infant and young child nutrition. Geneva: World Health Assembly; (WHA 55.25); http://www.who.int/gb/EB_WHA/PDF/WHA55/ ewha5525.pdf (accessed 2003-06-08) 2002.

27. Lipsky S, Stephenson PA, Koepsell TD, Gloyd SS, Lopez JL and Bain CE: Breastfeeding and weaning practices in rural Mexico Nutr Health 1994, 9:255-263.

28. Marques NM, Lira PI, Lima MC, da Silva NL, Filho MB, Huttly SR and Ashworth A: Breastfeeding and early weaning practices in northeast Brazil: a longitudinal study Pediatrics 200 I, I 08:E66..

29. Anonymous: Encuesta Nacional de Demografía y Salud Edited by: Instituto Nacional de Estadística La Paz Bolivia. Demographic and Health Surveys. Macro International Inc.; 1994.

30. Perez-Escamilla R: Breast-feeding patterns in nine Latin American and Caribbean countries Bull Pan Am Health Organ 1993, 27:32-42.

31. Dulon M, Kersting M and Schach S: Duration of breastfeeding and associated factors in Western and Eastern Germany Acta Paediatr 2001, 90:931-935.

32. Perez-Escamilla R, Segura-Millan S, Canahuati J and Allen H: Prelacteal feeds are negatively associated with breast-feeding outcomes in Honduras J Nutr 1996, I 26:2765-2773.

33. Perez-Escamilla R, Segura-Millan S, Pollitt E and Dewey KG: Determinants of lactation performance across time in an urban population from Mexico Soc Sci Med 1993, 37:1069-1078.

34. Kramer MS, Chalmers B, Hodnett ED, Sevkovskaya Z, Dzikovich I, Shapiro S, Collet JP, Vanilovich I, Mezen I, Ducruet T, Shishko G, Zubovich V, Mknuik D, Gluchanina E, Dombrovskiy V, Ustinovitch A, Kot T, Bogdanovich N, Ovchinikova L and Helsing E: Promotion of Breastfeeding Intervention Trial (PROBIT): a randomized trial in the Republic of Belarus Jama 200I, 285:4I 3-420.

35. Sikorski J, Renfrew MJ, Pindoria S and Wade A: Support for breastfeeding mothers Cochrane Database Syst Rev 2002, I:CD000 I I4I.

\section{Pre-publication history}

The pre-publication history for this paper can be accessed here:

http://www.biomedcentral.com/1471-2431/3/5/prepub
Publish with Bio Med Central and every scientist can read your work free of charge

"BioMed Central will be the most significant development for disseminating the results of biomedical research in our lifetime. "

Sir Paul Nurse, Cancer Research UK

Your research papers will be:

- available free of charge to the entire biomedical community

- peer reviewed and published immediately upon acceptance

- cited in PubMed and archived on PubMed Central

- yours - you keep the copyright

Submit your manuscript here:

http://www.biomedcentral.com/info/publishing_adv.asp
BioMedcentral 